\title{
How Well Does the U.S. Government Do Benefit-Cost Analysis?
}

\author{
Robert W. Hahn and Patrick M. Dudley*
}

\section{Introduction}

Over the past several decades there have been numerous critiques of the application of economic approaches to problems in public policy. Several books and articles have been written that criticize benefit-cost analysis and economic policy analysis more broadly (Ackerman and Heinzerling 2002). There have also been a number of defenses of economic approaches to analyzing important public policy issues. For example, Justice Breyer argues that government should set regulatory priorities differently so that more lives can be saved with a given level of expenditures (Breyer 1993). Sunstein (2002) takes a different approach but also supports the expanded use of benefit-cost analysis.

The debate over the use of economic analysis as a tool in regulatory decision making is more than academic. Countries and states throughout the world are beginning to require extensive use of benefit-cost analysis and related tools as a way of informing key regulatory decisions and reforming the regulatory process. In the United States, for example, the Office of Management and Budget (OMB) — the agency charged with regulatory oversight — is using benefit-cost analysis to both improve regulatory proposals and stimulate the implementation of new measures where the benefits exceed the costs (OMB 2002).

The use of benefit-cost analysis has been particularly controversial in the area of environmental, health, and safety regulations (Adler and Posner 2000). According to government estimates, the costs associated with such regulations are substantial - on the order of $\$ 200$ billion (in 1996 dollars) annually (OMB 2001). The benefits, which are harder to pin down, may be even larger, although the net benefits (or costs) of individual

\footnotetext{
*Mr. Hahn is co-founder and executive director of the American Enterprise Institute-Brookings Joint Center for Regulatory Studies and a scholar at AEI. Mr. Dudley is a former researcher at the AEI-Brookings Joint Center. The authors would like to thank Gregory Besharov, Cary Coglianese, Scott Farrow, Art Fraas, Myrick Freeman, John Graham, Scott Jacobs, Randy Kroszner, Lester Lave, Randy Lutter, Al McGartland, Richard Morgenstern, Sheila Olmstead, Paul Portney, Eric Posner, James Prieger, Kerry Smith, Robert Stavins, Paul Tetlock, Scott Wallsten, Richard Zeckhauser, and seminar participants at Harvard University for helpful comments. The authors would also like to thank Caroline Cecot, Jordan Connors, Laura Goodman, Jesse Gurman, Elisabeth Irwin, Katrina Kosec, Troy Kravitz, Rohit Malik, Mary Beth Muething, and Shenyi $\mathrm{Wu}$ for help with this research. The views expressed in this article represent those of the authors and do not necessarily represent the views of the institutions with which they are affiliated.
}

Review of Environmental Economics and Policy, volume 1, issue 2, summer 2007, pp. 192-211 doi: $10.1093 /$ reep/rem012 
regulations can vary significantly (OMB, 2001; Hahn, 2000; Freeman, 2002; Morrall, 2003). Thus, making even relatively modest changes in the regulatory apparatus could have significant implications for the public's health and welfare.

Economists generally believe that benefit-cost analysis is a useful tool for helping decision makers better assess the impact of policies (Lave, 1982; Viscusi, 1996; Portney, 1990; Arrow et al., 1996). Benefit-cost analysis can help decision makers select policies with positive net social benefits, identify the likely winners and losers as a result of a policy, evaluate the impact of uncertainty on the net benefits of different policies, and assess the potential value of new information (Stokey and Zeckhauser, 1978; Raiffa, 1970).

Benefit-cost analysis can also help identify key deficiencies in our understanding of a particular policy issue and show how sensitive the results are to different assumptions (Viscusi and Hamilton 1999). For example, an analyst may be able to quantify the likely economic costs of requiring passengers to have their bags screened at airports but may not be able to assess the likely benefits of such a policy. An analysis of an environmental regulation may highlight that we do not really understand the pathway by which humans are exposed. In short, benefit-cost analysis can provide a useful framework for understanding the implications of different policy choices and whether a proposed regulation offers social net benefits (Sunstein 2002).

Scholars differ over the extent to which benefit-cost analysis should be used as a tool for making policy choices. Some take the view that before a government policy is implemented, there needs to be reasonable evidence that the benefits of that policy are likely to exceed the costs and that the particular option chosen offers the highest expected net benefits (Crandall et al., 1997). Others believe that the decision maker should have more discretion but that benefit-cost analysis can provide a useful input into policy making (Arrow et al., 1996; Sunstein, 2002). Still others believe that benefit-cost analysis is not terribly useful in a number of settings because of practical or theoretical problems (Chichilnisky, 1997; Kelman, 1981).

Economics, as a profession, should take special interest in benefit-cost analysis. Outside of the Federal Reserve, this may be the area of public policy where economic ideas are used most often. Knowing the strengths and weaknesses of these analyses will help economists both inside and outside the government understand how benefit-cost analysis can be more effectively used to improve public policy.

In order to make prudent recommendations for improving the use of benefit-cost analysis in policy settings, we need to have some measures of how well such analyses are actually done, since the utility of a particular analysis depends, in large part, on its quality. Of course, even a reasonably good analysis does not assure that the ensuing decision will be sensible. But if the analysis is poor, it is certainly more likely that decision makers will make poor decisions. So, for example, a poor analysis of a water quality regulation could lead to the selection of a policy that results in lower levels of water quality than might be achieved with a policy that could have been selected with a better analysis.

The purpose of this article is to examine how benefit-cost analysis is actually performed by U.S. government agencies. To this end, we assess the quality of a sample of seventyfour benefit-cost analyses of federal environmental regulations from the Environmental Protection Agency (EPA) that span the Reagan administration, the first Bush administration, and the Clinton administration. This article is the first to assess systematically how 
government benefit-cost analysis has changed over time and uses the largest data set assembled to date. ${ }^{1}$

Our analysis is possible because since 1981, the U.S. government has required that a benefit-cost analysis be conducted for all economically significant federal regulations - regulations that frequently cost billions of dollars annually. Even though they are ex ante analyses, these RIAs represent the most comprehensive set of data about the consequences of regulation in the United States.

The article has three key findings related to the actual practice of benefit-cost analysis. First, a significant percentage of the analyses done by the EPA do not report some very basic economic information. Second, there is no clear trend in the quality of benefit-cost analysis across administrations. Third, there is a great deal of variation in the quality of individual benefit-cost analyses.

The remainder of this article is organized as follows: the second section provides some institutional and historical background on the use of benefit-cost analysis in regulatory decision making in the United States. The third section describes the main approaches for measuring the quality of regulatory analyses and presents the analytical approach used in this study. The fourth section describes the results of our analysis. The fifth section discusses implications of the results and offers some policy recommendations. The sixth section is the conclusion.

\section{Government Requirements for Benefit-Cost Analysis of Regulation}

Federal regulation has grown dramatically in the last fifty years. Although regulations resulting from legislative mandates often have little direct fiscal impact, they pose real costs to consumers and businesses. Initially, however, the economic impacts of federal regulation received much less scrutiny than discretionary programs in the budget, even though such regulations have important implications for economic efficiency. Early efforts to rationalize the regulatory process can be traced to Presidents Nixon, Ford, and Carter, but much more significant action started with President Reagan (Weidenbaum 1997).

Over the last two decades, both Congress and the executive branch have initiated regulatory reforms in order to better assess the impacts of regulation on economic activity and to encourage the development of more effective and efficient regulations (Sunstein, 2002; Hahn, 2000; Renda, 2006). For example, Presidents Reagan, Bush, and Clinton directed all agencies to perform economic analyses of major regulations that show whether a regulation's benefits were likely to exceed its costs and whether alternatives to that regulation would be more effective or less costly. Each president also attempted to increase agency accountability for decisions by requiring that $\mathrm{OMB}$ review all major regulations. More recently, Congress has also embraced regulatory reform. For example, Congress inserted analytical requirements and accountability mechanisms, including regulatory oversight,

\footnotetext{
${ }^{1}$ Hahn et al. (2000), General Accounting Office (GAO) (1997), GAO (1998), Smith (1984), and Morgenstern (1997), among others, evaluate a significant number of regulatory impact analyses (RIAs), but none focuses on whether there is a time trend.
} 
sunset provisions, regulatory budgets, and peer review, into laws such as the Safe Drinking Water Act Amendments of 1996, the Small Business Enforcement and Fairness Act of 1996, and the Unfunded Mandates Reform Act of 1995. In addition, Congress has passed laws that require $\mathrm{OMB}$ to produce regular reports on the costs and benefits of federal regulation (e.g., OMB, 2004; OMB, 2005).

The most prominent and far-reaching of these regulatory reform efforts are President Reagan's Executive Order 12291 and President Clinton's Executive Order 12866. ${ }^{2}$ Both of these executive orders require agencies to prepare an RIA for all major federal regulations.

Thus, agencies have been preparing RIAs for over twenty-five years. The basic requirements placed on agencies have remained constant, even though some of the details have changed. Both Executive Order 12291 and 12866 require agencies to consider all significant costs and benefits, including those that cannot be quantified. Furthermore, agencies must consider all alternatives and choose the one that maximizes net benefits or minimizes net costs. ${ }^{3}$ Both executive orders place OMB in charge of overseeing the regulatory process. However, Clinton's Executive Order 12866 places more emphasis on distributional concerns and public transparency of the regulatory process. Executive Order 12866 also requires agencies to show that the benefits "justify" the costs, in contrast to Reagan's Executive Order 12291, which requires that the benefits "outweigh" the costs. Both allow for analyzing some effects in qualitative terms only. Reagan's Executive Order 12291 acknowledges that some effects "cannot be quantified in monetary terms," while Clinton's Executive Order 12866 specifically calls for quantifiable measures "to the fullest extent that these can be usefully estimated."

The OMB has issued guidelines and memos instructing agencies on how to comply with the relevant executive orders (OMB Guidelines 1996). The EPA also issued its own set of guidelines detailing how RIAs should comply with the executive orders (EPA 1983). The basic instructions, such as quantifying as many costs and benefits as possible and evaluating alternatives, have remained constant over the past twenty-five years. These are the elements of the RIA that we examine below.

\section{Assessing the "Quality" of Regulatory Analyses}

The quality of a benefit-cost analysis is intrinsically hard to measure. There are essentially three approaches for measuring the quality of regulatory analyses. One is to have experts carefully examine the details of a particular benefit-cost analysis or group of analyses, such as key assumptions and results (Morgenstern, 1997; Smith, 1984; Sunstein, 2002; Lutter and Gruenspecht, 2001; White, 1981). The main advantage of such a case-study approach is that detailed analysis of individual cases can highlight the strengths and weaknesses of

\footnotetext{
${ }^{2}$ President George W. Bush recently amended Executive Order 12866. The basic thrust of the new order is the same with regard to economic analysis of regulations, but the new order also requires more careful scrutiny of regulatory guidance from agencies.

${ }^{3}$ This requirement does not apply if the law forbids it, as is the case with setting national ambient air quality standards. Executive Order 12291, however, specifically calls for the analysis of alternative approaches that could result in higher net benefits along with an explanation of the legal reasons why the alternatives could not be adopted.
} 
the data, assumptions, and underlying models. A major weakness of this approach is that the analytical methods are not easily generalized and the results are not easily replicated. Furthermore, reasonable people may disagree about the relative quality of analyses because of the highly subjective nature of the case-study approach.

The second approach uses estimates of a key parameter, such as net benefits or costeffectiveness, from studies done before and after the implementation of a policy (Harrington et al., 2000; OMB, 2005). The idea is that the estimate done after a study provides a better measure of the actual impact of a policy. This approach poses a number of challenges from the standpoint of measuring quality. First, it depends on the state of information available when the studies are done. Second, analyses done before and after the fact could differ for a number of reasons related to methodology and assumptions, and this needs to be taken into account. Third, there have been relatively few studies of this kind because accurately estimating the ex post effects of a regulation can be difficult and costly, and there is little political payoff in having such estimates. ${ }^{4}$

A third method is to score a large number of benefit-cost analyses according to whether they meet a number of basic, objective criteria, such as whether some costs and benefits were monetized, whether costs and benefits were discounted, and whether alternatives were considered (Hahn et al., 2000; GAO, 1997; GAO, 1998).

A great advantage of the scorecard method is that it requires no detailed knowledge of the assumptions and calculations underlying a particular analysis, and does not require the researchers to judge whether the estimates are correct or based on sound science, only whether or not they were presented in an RIA. The definition of a good RIA is very specific - it follows the basic requirements set forth in the executive orders and OMB guidelines. In this sense, the scorecard is objective, and other researchers should be able to reproduce the results.

A potential disadvantage to this focus on reporting, rather than on the underlying assumptions or methods, is that an RIA could receive a high score and still be poorly done. In the extreme, an RIA could receive a perfect score if all of the appropriate estimates are included but still be of low quality if all of the estimates are wrong. In other words, the scorecard approach precludes critical evaluation of the agency estimates, which may be biased or compromised by analytical flaws. However, since many of the questions on the scorecard are quite basic, an RIA with a low score is unlikely to be of high quality.

Furthermore, the scorecard does not measure the impacts that RIAs may have on the process of regulation itself, such as increasing transparency, encouraging debate, or changing policy. Such benefits are potentially significant, but they cannot be captured by the scorecard used in this study.

\section{Approach of the Current Study}

This study uses the scorecard method described above to identify common strengths and weaknesses among a relatively large sample of RIAs. We assess the quality of seventy-four agency RIAs by testing how well they meet the government's own standards for economic

${ }^{4}$ Politicians are typically not interested in supporting analyses of regulations and programs because they are costly and have the potential to put initiatives they support in a bad light. 
analysis, as described in executive orders 12291 and 12866 and the OMB guidelines (Reagan, 1981; Clinton, 1993; OMB, 1996). ${ }^{5}$

Executive Order 12866 states, for example, that agencies shall provide "an assessment, including the underlying analysis," of benefits and costs expected from a regulation and, "to the fullest extent," provide a quantification of those benefits and costs. The OMB guidelines further direct agencies to express benefits and costs in monetary terms "to the fullest extent possible." In addition, they identify and discuss principles for placing an explicit value on benefits that are difficult to monetize, such as environmental amenities (OMB 1996). Executive Order 12866 also requires that agencies specifically assess the effects of regulations on state, local, and tribal governments. In addition, Executive Order 12866 states that "agencies should assess all costs and benefits of available regulatory alternatives, including the alternative of not regulating" (Clinton, 1993, $\$ 1(a)$ ). The OMB guidelines further provide agencies with a recommended approach for evaluating alternatives, such as urging agencies to define carefully the proper baseline, to discuss uncertainty and bias in estimates, and to carefully describe key assumptions used in developing estimates of benefits and costs (OMB 1996). The EPA guidelines even list the types of alternatives that may be considered when evaluating a proposal. Finally, according to Executive Order 12866, the RIA must provide sufficient information to demonstrate that the agency is selecting the regulatory approach that maximizes net benefits, unless the approach is prohibited by statute.

Based on the executive orders and OMB guidelines, the authors developed a "regulatory scorecard" consisting of a series of yes/no questions, such as: Did the RIA state that costs exist? Did the RIA monetize at least some benefits? Did the RIA calculate a measure of cost-effectiveness? Each item listed on the scorecard represents an essential element of a good economic analysis. The questions on the scorecard are similar to those used in previous research (Hahn et al., 2000) and are available as supplementary material linked to the article.

\section{The Sample}

The sample used in this study consists of a total of seventy-four RIAs - twenty-seven from the Reagan administration, twenty-four from the George H. W. Bush administration, and twenty-three from the Clinton administration. The RIAs were published from 1982 to 1999. All of the RIAs were from the EPA. The EPA was selected because it accounts for a majority of all available regulatory analyses and more than half of the total costs of regulation (Hahn, 2000; OMB, 2001). We chose to focus on a single agency to minimize variations in quality across agencies. In addition, many agencies have not written enough RIAs to form a significant sample for each administration. While there has been some analyses comparing RIAs across agencies, they have suffered from small sample sizes (GAO, 1998; Hahn et al., 2000).

The sample includes as many available RIAs as could be found from 1982 to 1992 and all of the Clinton-era EPA rules included in Hahn et al. (2000), which covered all rules published in the Federal Register between April 1996 and July 1999. With a few exceptions, such as rules passed under emergency circumstances, agencies produce RIAs for all major

${ }^{5} \mathrm{~A}$ list of the seventy-four RIAs studied is available as supplementary material linked to the article. 
rules. Although there is some overlap, this sample is different from Hahn et al. (2000), which examined multiple agencies during one administration. This study examines one agency across multiple administrations. RIAs were obtained through web searches, through searches of the agency's dockets, and through officials at the OMB, the EPA, and the GAO.

Our search was thorough, and our sample is larger than that of any previous efforts. We acknowledge, however, that we may be missing some RIAs written during the Reagan and Bush administrations because until Congress required the OMB to issue annual reports on regulation in the mid-1990s, there was no official public record of which regulations had been analyzed under the executive orders. Nor were agencies required to keep copies of old RIAs. The most exhaustive public record of environmental RIAs we could find was kept by the National Center for Environmental Economics, a division of the EPA. We thoroughly checked this library for RIAs both online and at EPA headquarters. ${ }^{6}$

Because more environmental rules were passed during the Clinton administration than during those of Reagan or Bush, we decided that we did not need the entire eight years in order to make a fair comparison. Therefore, we chose the RIAs used in Hahn et al. (2000). The RIAs themselves were written between 1993 and 1999, representing six years of the Clinton administration. We decided not to cover the current Bush administration because there were not sufficient data when we began our research. ${ }^{7}$

This study includes rules that address market failures, such as improving air quality. It excludes "transfer" rules, which are rules designed to move resources from the federal government to designated segments of the population, because agencies generally do not assess the costs and benefits of such rules (OMB, 2001; OMB, 2002).

\section{Results}

The results of our analysis point to three key findings. The first finding is that quality of the analyses, as measured by the inclusion of fundamental economic information, is generally low. The second finding is that the quality of the benefit-cost analyses does not seem to change over time and across administrations. The third finding is that individual RIAs vary widely in quality even within administrations. These results are discussed in more detail below.

\section{Inclusion of Fundamental Economic Information}

The findings concerning the inclusion of fundamental economic information are divided into six categories: costs, benefits, comparison of costs and benefits, consideration of alternatives, clarity of presentation, and the use of analytical assumptions.

\footnotetext{
${ }^{6}$ We know we are missing RIAs for four rules for which we could not find complete information. These are listed in the supplementary material linked to the article.

${ }^{7}$ Note that electronic copies of all the documents used in this study, as well as RIAs from other agencies, can be found in the RIA database at www.aei-brookings.org.
} 


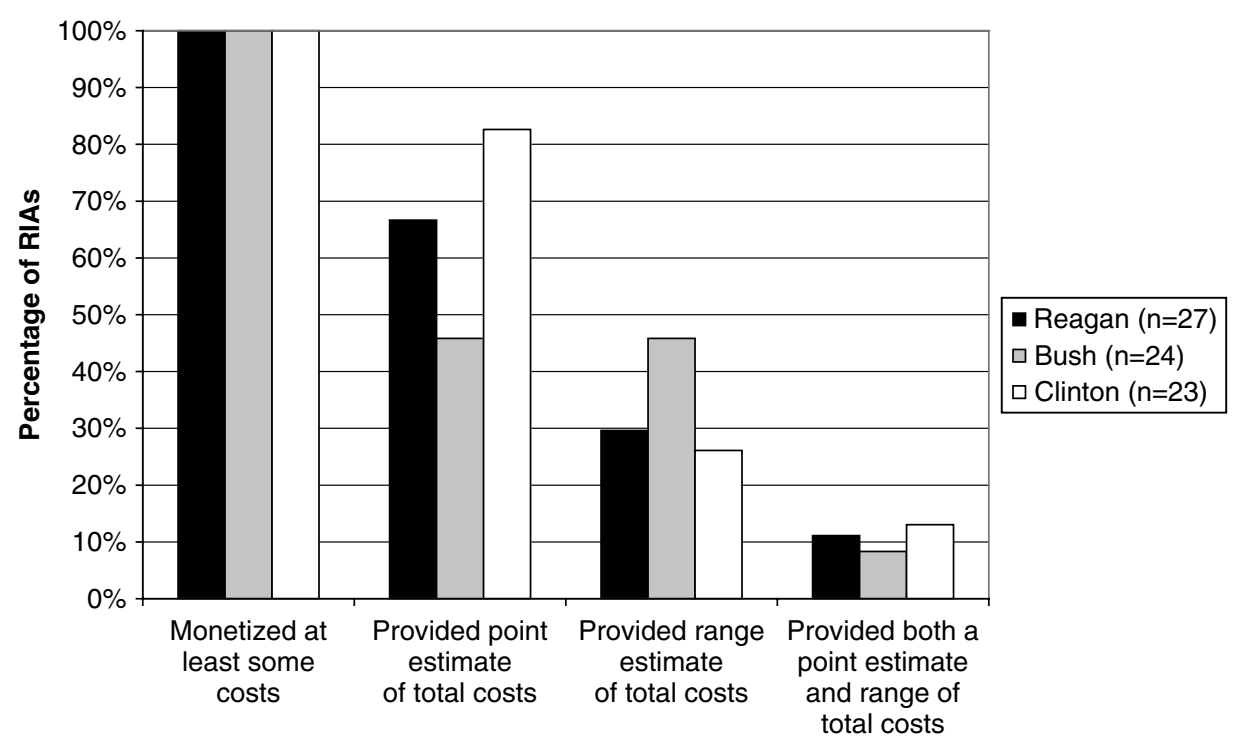

Figure I. Analysis of costs.

\section{Costs}

The EPA has consistently presented cost estimates in RIAs done during the Reagan administration, the first Bush administration, and the Clinton administrations. Figure 1 summarizes the key results on costs. All RIAs stated that costs exist, quantified at least some costs, and monetized at least some costs. Costs are considered to be quantified if they are expressed in some countable unit, such as dollars, labor hours, or new machinery. They are considered monetized if those units are assigned monetary values, such as stating that the cost of compliance will be one hundred million dollars. Monetization implies quantification, but not vice versa.

Not all RIAs gave an estimate of total costs. ${ }^{8}$ In the Reagan administration, 15 percent of the RIAs provided neither a point estimate nor a range for total costs. ${ }^{9}$ During the Bush administration, 17 percent provided neither a point estimate nor a range, and during the Clinton administration, 4 percent provided neither a point estimate nor a range. During the Reagan and Clinton administrations, point estimates of total costs were more common than ranges. During the Bush administration, point estimates were as common as ranges. The reason for this is not clear. Few RIAs provided both a point estimate and range during any administration.

While virtually all of the RIAs studied included estimates of costs to producers (over 90 percent for all administrations), fewer included estimates of administrative costs to

\footnotetext{
${ }^{8} \mathrm{An}$ estimate of total costs is defined as an estimate that is summed across regions of the country, affected industries, subsections of the rule or other relevant subtotals. The cost from a case study, which may apply to one or a few plants, is not considered to be an estimate of total cost.

${ }^{9} \mathrm{~A}$ point estimate is defined as an estimate that is a single number, as opposed to a range. A range estimate is defined as an estimate that includes two points and is inclusive of a significant portion of the confidence interval of an estimate. Note that two case studies do not count as a range of total costs.
} 


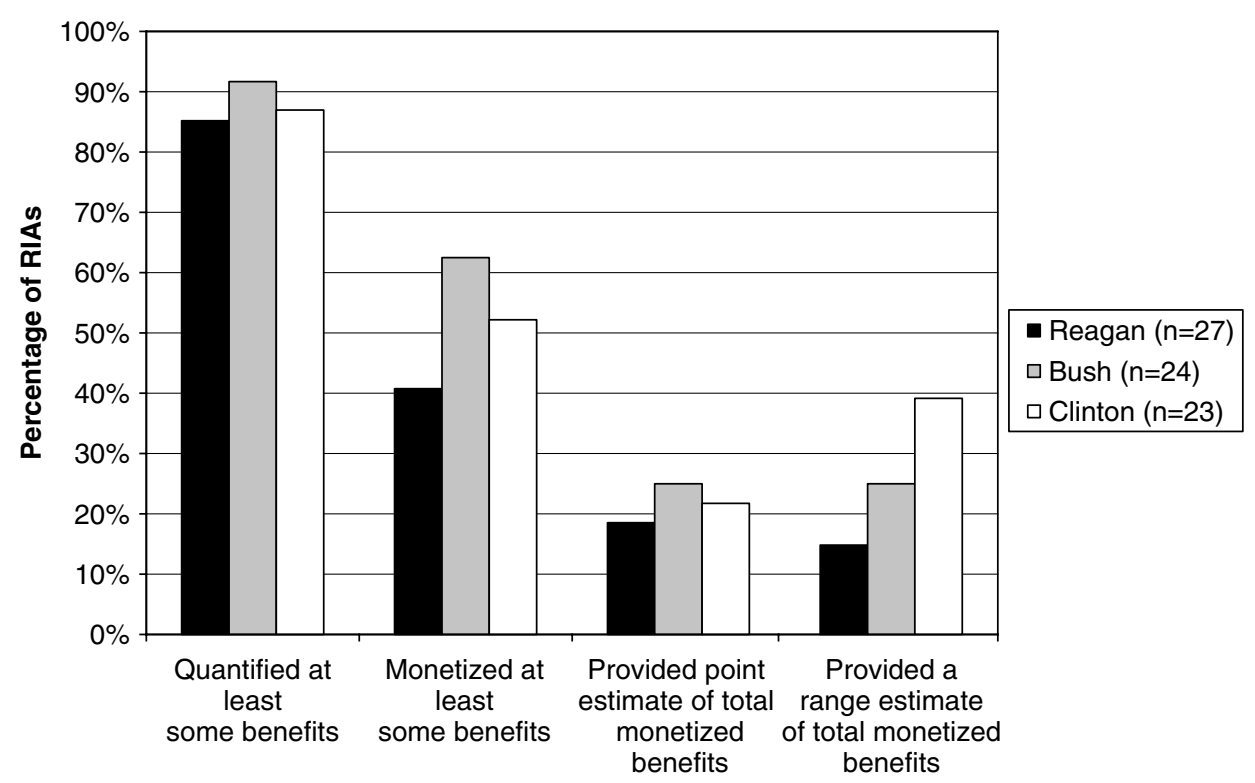

Figure 2. Analysis of benefits.

the federal government (30 percent or fewer for all administrations) or to state and local governments (50 percent or fewer).

\section{Benefits}

As shown in Figure 2, the RIAs did not present estimates of benefits as consistently as costs. Like costs, benefits are considered to be quantified if they are expressed in some countable unit, such as dollars, lives saved, or tons of pollution reduced. They are considered monetized if those units are assigned monetary values. While 100 percent of the RIAs monetized at least some costs, only about 50 percent monetized at least some benefits. The number of RIAs that quantified at least some benefits was significantly higher-exceeding 80 percent for all three administrations. This result suggests that some benefits are not easily monetized and/or that the agency is reluctant to monetize some benefits.

In contrast to the cost estimates, estimates of total monetized benefits were fairly evenly divided between analyses that reported point estimates and those that reported ranges. As with the estimates of costs, providing both a point estimate and a range for total monetized benefits was rare - 13 percent or less for all three administrations. Overall, while many RIAs quantified benefits and a significant number monetized benefits, the estimation of benefits lags well behind the estimation of costs.

\section{Comparison of costs and benefits}

Economists frequently focus on measures of net benefits. Comparing costs and benefits gives decision makers a deeper insight into the likely impact of different policies in terms of their net benefits or the costs of achieving various goals. Unfortunately, as summarized in Figure 3, the EPA has not consistently used these measures. During the Clinton administration, the EPA calculated at least one measure of net benefits 39 percent of 


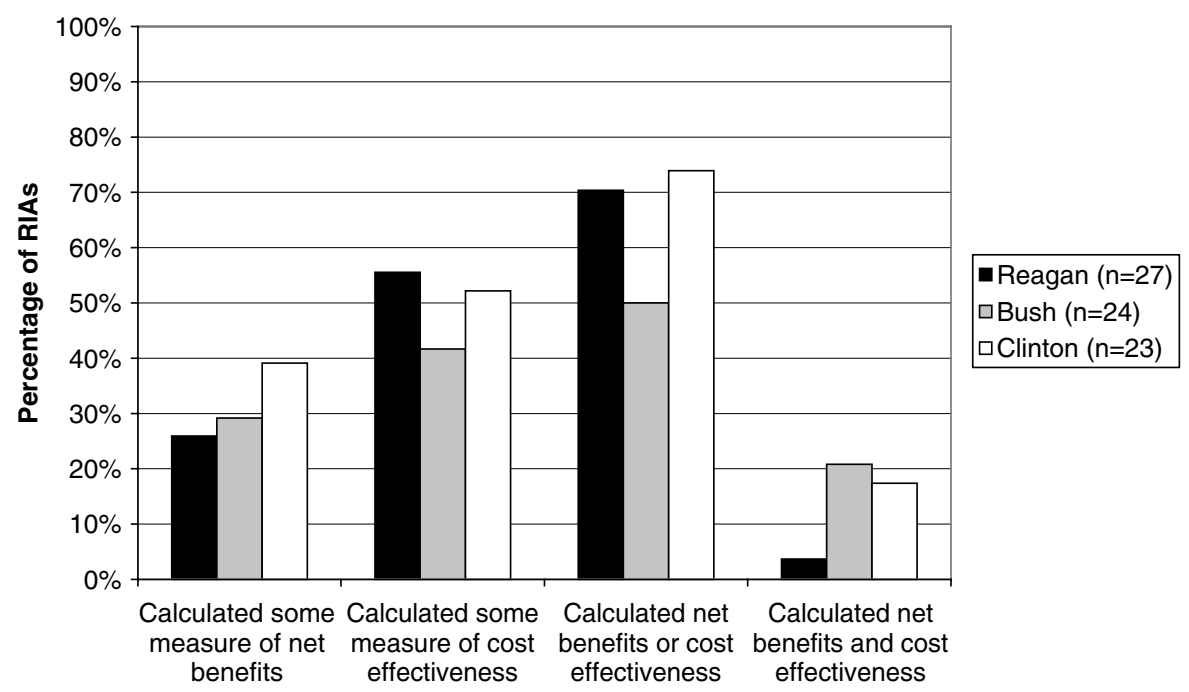

Figure 3. Analysis of net benefits and cost-effectiveness.

the time, compared with 26 percent during the Reagan administration and 29 percent during the Bush administration. For cost-effectiveness, the numbers were somewhat higher -52 percent for Clinton, 56 percent for Reagan and 42 percent for Bush. It is not surprising that cost-effectiveness was calculated more often than net benefits. This is because calculation of net benefits requires monetized costs and monetized benefits, while calculation of cost-effectiveness requires only monetized costs and quantified benefits. All RIAs monetized at least some costs, but more RIAs quantified rather than monetized benefits. Therefore, more RIAs had the information necessary to calculate cost-effectiveness rather than net benefits.

RIAs tended to calculate either cost-effectiveness or net benefits, rarely both. During the Clinton administration, 74 percent of the RIAs calculated a measure of either net benefits or cost-effectiveness. For the Reagan and Bush administrations, the numbers were lower-70 and 50 percent, respectively. No more than 21 percent of RIAs in any administration reported both net benefits and cost-effectiveness.

These findings illustrate how difficult it would be to use basic quantitative information on net benefits or cost-effectiveness for decision making. In 35 percent of the regulations examined here, such information simply is not reported. Indeed, net benefit information does not exist for 69 percent of the RIAs in the sample. However, EPA does not appear to be using all of the quantitative information that it does have to calculate net benefits and costeffectiveness. Of the rules in the sample that monetized benefits, only 58 percent calculated net benefits. Of the rules in the sample that quantified benefits, only 74 percent calculated cost-effectiveness or net benefits. This suggests that comparisons of costs and benefits are not occurring in a large number of cases for which the necessary data are actually available.

As shown in Figure 4, there are some differences in the presentation of these data across administrations. In all three administrations, the EPA preferred point estimates to ranges for total cost-effectiveness. But for total net benefits during the Reagan and Clinton administrations, however, the EPA preferred ranges to point estimates. In addition, the percentage of RIAs presenting total cost-effectiveness estimates has grown across 


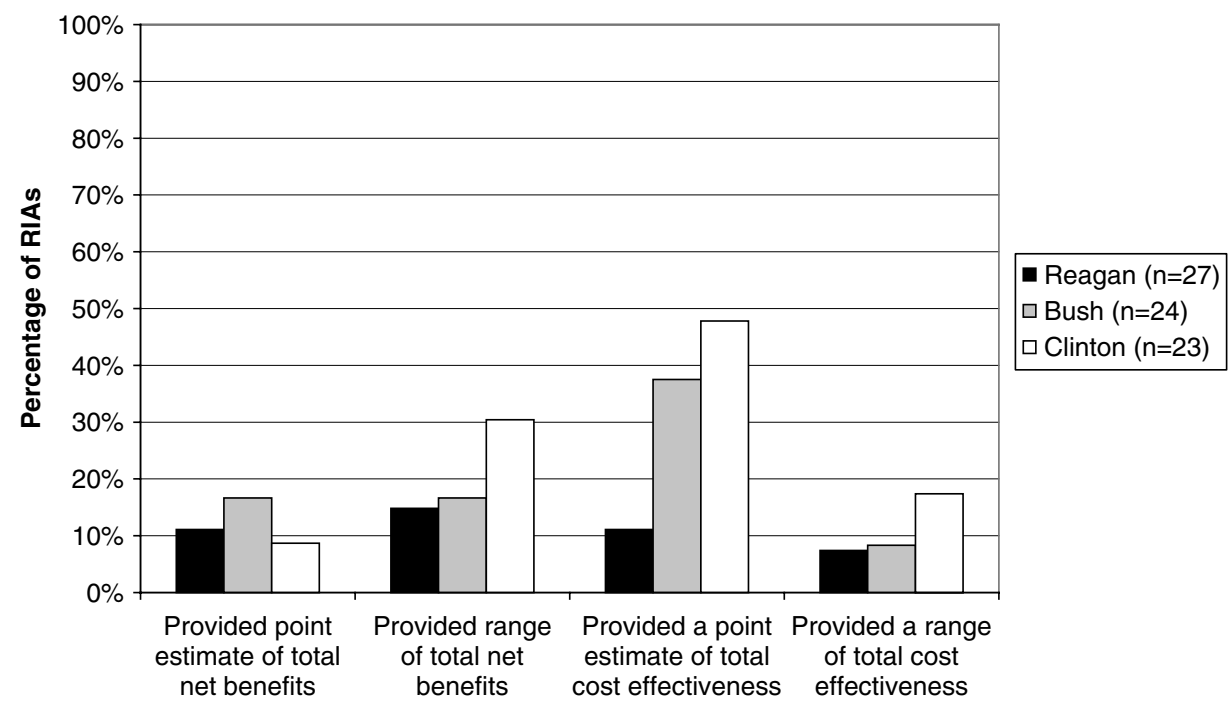

Figure 4. Point estimates and ranges for net benefits and cost-effectiveness.

administrations. During the Reagan administration, only 37 percent of RIAs presented a point or range estimate of total cost-effectiveness. That number increased to 42 percent during the Bush administration and to 48 percent during the Clinton administration. An RIA could get credit for some measure of cost-effectiveness, but not for a total estimate of cost-effectiveness, if for example, it calculated the cost-effectiveness using only a case study estimate instead of a national average. A cost-effectiveness estimate was scored as a total estimate if the numerator (the costs) met the definition of total cost given above.

\section{Consideration of alternatives}

Evaluation of alternatives is critical in determining which policies yield the highest net benefits. An alternative is defined as any policy that seeks to achieve the same end through a different method (e.g., self-regulation or pollution trading or taxation) or at a different level (e.g., emissions are capped but at a higher or lower level). In this study, not regulating was considered an alternative if the RIA provided specific calculations or an analysis of that scenario. Background information on externalities or market failures was not scored as an analysis of not regulating.

Figure 5 provides some key statistics on the consideration and presentation of alternatives in the RIAs. For several items on the scorecard, the reporting on alternatives has gotten worse over time. The percentage of RIAs that considered at least one alternative standard or level decreased from 85 percent during the Reagan administration to 74 percent during the Clinton administration. The percentage that monetized the costs of alternatives dropped from 78 percent to 43 percent and the percentage that quantified the benefits of alternatives decreased from 59 percent to 35 percent. In contrast, there has been no decline in the monetization of benefits of alternative policies.

In terms of net benefits and cost-effectiveness, there has been a general pattern of incomplete comparisons of alternatives (see Figure 6). The percentage of RIAs that calculated cost-effectiveness of alternatives decreased across administrations, from 37 percent during 


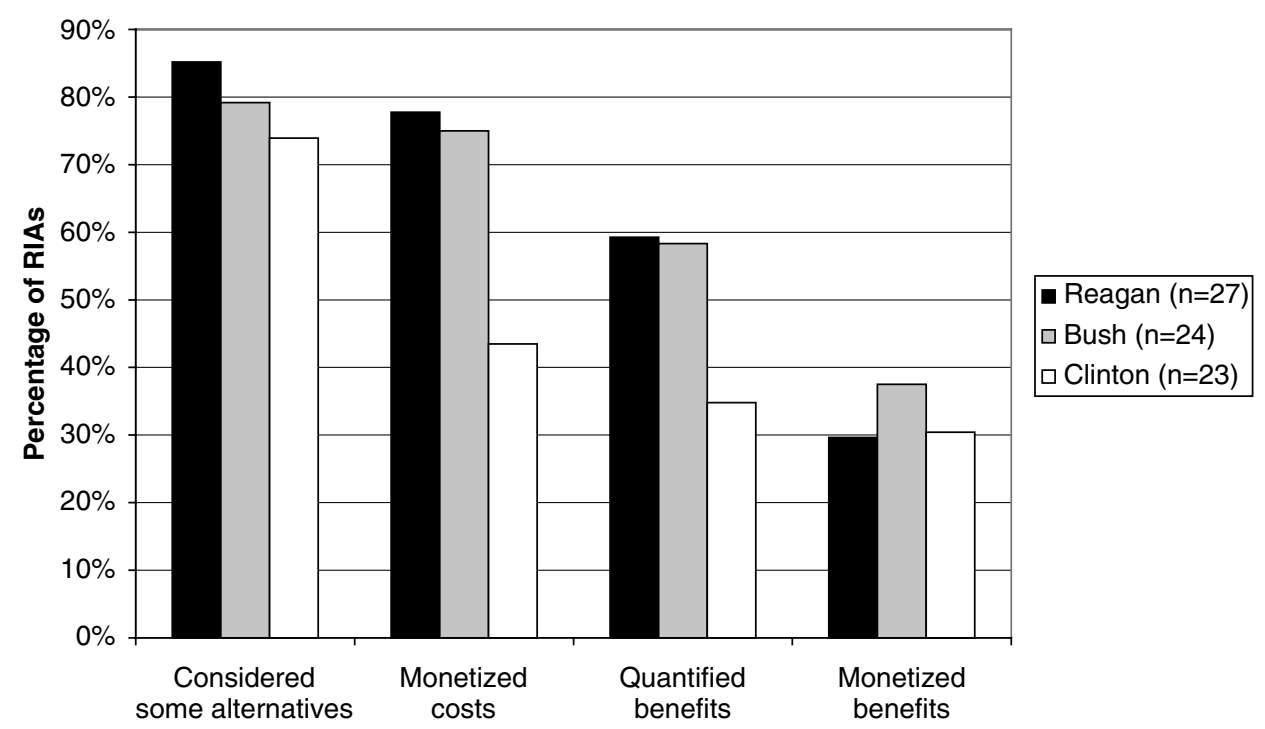

Figure 5. Consideration of alternatives.

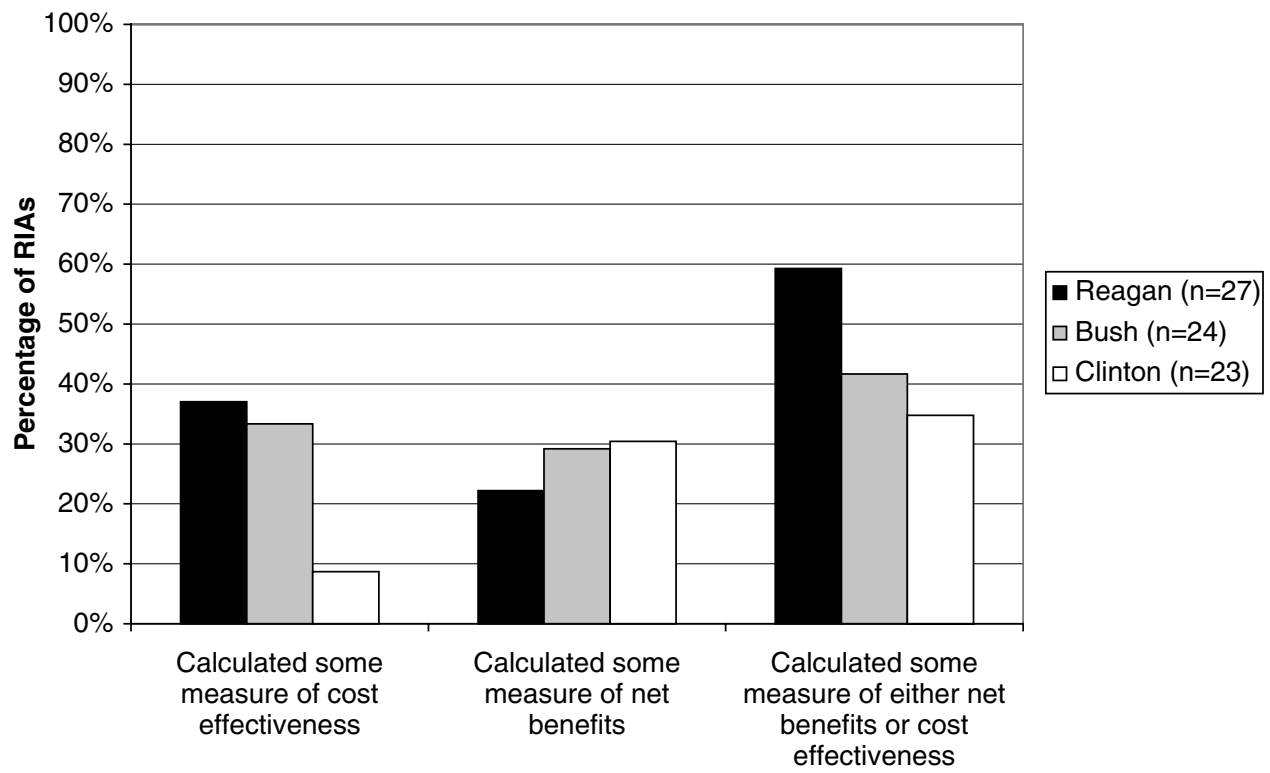

Figure 6. Cost-effectiveness and net benefits of alternatives.

the Reagan administration to 33 percent during the Bush administration to 9 percent during the Clinton administration. The calculation of the net benefits of alternatives was not very common either, with only 27 percent of the RIAs calculating any net benefits of alternatives. The percentage of RIAs that calculated either net benefits or cost-effectiveness of alternatives peaked at 59 percent in the Reagan administration and averaged 46 percent for all RIAs. 


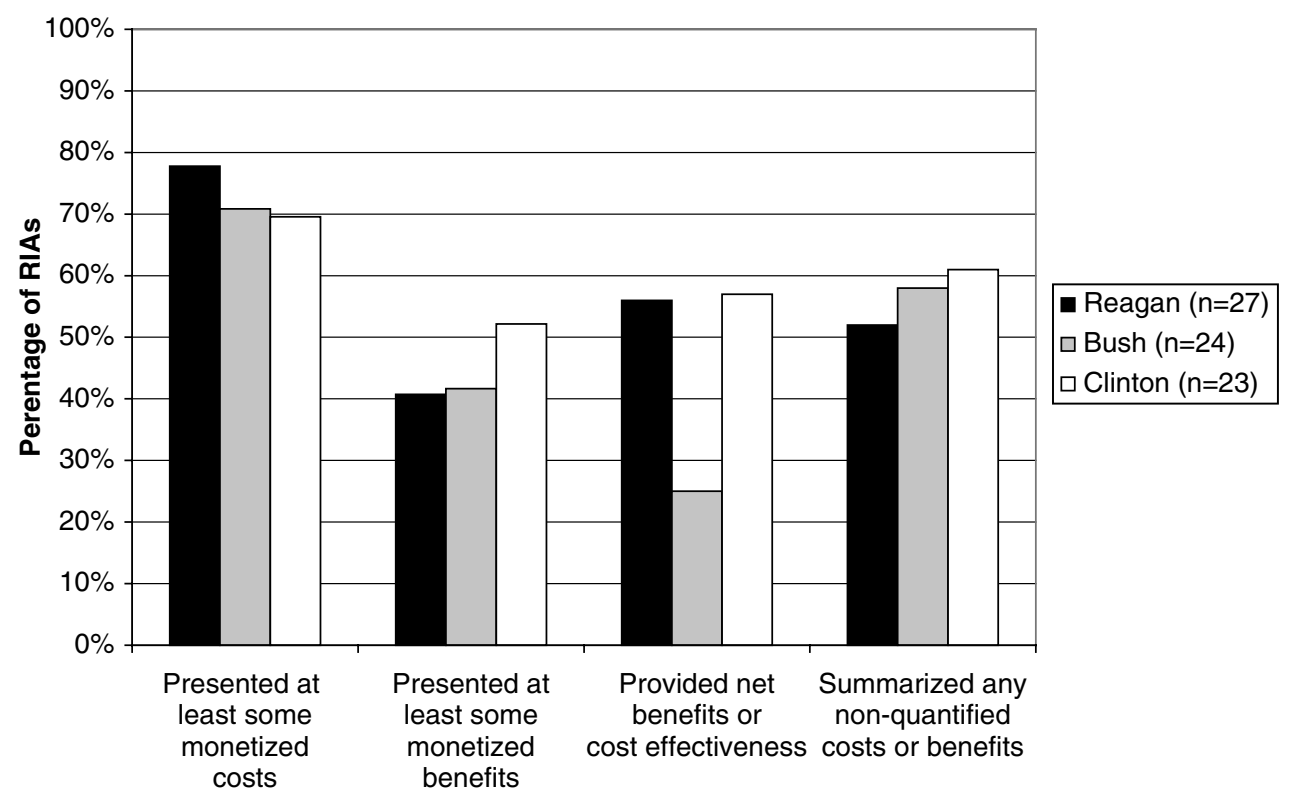

Figure 7. Executive summary.

\section{Clarity of presentation}

In addition to presenting estimates of costs and benefits, RIAs should help the public understand the EPA's decisions. In fact, the objective of Executive Order 12866 was to make the process "more accessible and open to the public." A clear and transparent presentation is vital to fulfilling this goal. Since RIAs are often hundreds of pages long, it is important for RIAs to have an executive summary (called an introduction in some RIAs). Approximately 80 percent of the RIAs included an executive summary. Figure 7 summarizes the content of these executive summaries. Overall, the percentage of RIAs that included an executive summary decreased from 85 percent during the Reagan administration to 70 percent during the Clinton administration. The percentage of RIAs that included an executive summary with some monetized costs decreased from 78 percent during the Reagan administration to 70 percent during the Clinton administration. The percentage that included an executive summary with some monetized benefits increased from 41 percent during the Reagan administration to 52 percent during the Clinton administration. Approximately 46 percent had executive summaries that compared costs and benefits, ranging from about 25 percent during the first Bush administration to about 57 percent during the Clinton administration. Although most of the RIAs contained executive summaries, only a small fraction of them included all of the key calculations from the RIA.

\section{Use of analytical assumptions}

A clear statement of important assumptions is essential to understanding an RIA. So, too, is the consistent application of basic ideas. Since an assessment of all key parameters was impossible, we examined the discount rate and the dollar year-two parameters that are critical to most RIAs. Including this information helps interested parties understand the 


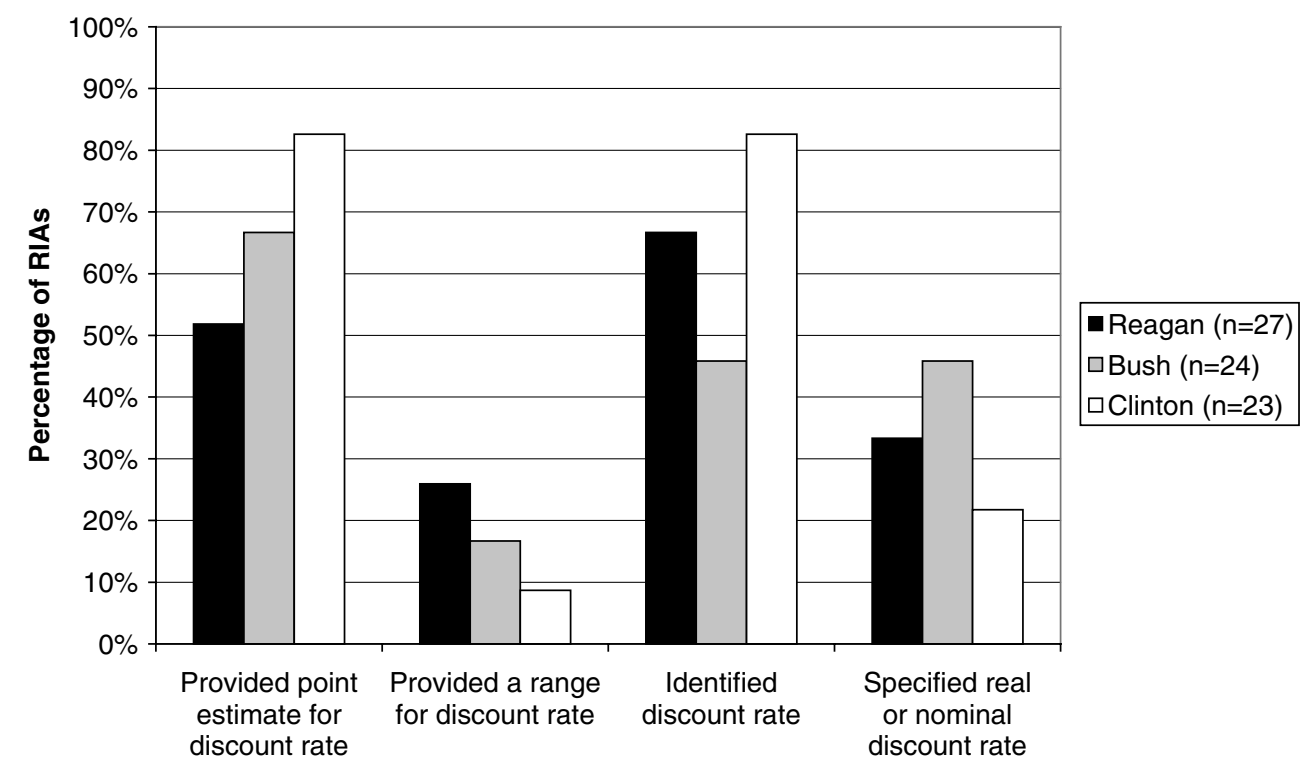

Figure 8. Discount rate.

results. Furthermore, many regulations have an important time component, meaning that either costs or benefits are spread out over multiple years. Failing to use the same dollar year or to discount future cash flows can be problematic when benefits and costs vary across time.

The dollar year was identified in 73 percent of the RIAs, with a low of 69 percent during Bush and a high of 78 percent under Clinton. The discount rate was identified with similar frequency: 67 percent during the Reagan administration, 75 percent during the Bush administration and 83 percent during the Clinton administration. Figure 8 summarizes the presentation of the discount rate across administrations. Despite continuing academic debate over the correct discount rate to use in policy making, a point estimate is much more common than a range estimate under all three administrations. Also, fewer than half of the RIAs specified whether the discount rate was real or nominal.

\section{Implications for Compliance with Executive Orders and OMB Guidelines}

Although low scores on our scorecard strongly suggest noncompliance with executive orders and $\mathrm{OMB}$ guidelines, they do not prove it. Both executive orders make exceptions for cases where information is difficult to obtain. It may be the case that all the items not included on an RIA were those that were difficult to obtain. In addition, some of the items we included on our scorecard are not explicitly required by the executive orders and OMB guidelines, though we think they are important components of a strong RIA. Nevertheless, we believe that there is evidence of at least some noncompliance with the executive orders and OMB guidelines.

For example, although both executive orders clearly require an assessment of all costs and benefits of alternative approaches, fourteen RIAs do not examine alternatives. Since the EPA guidelines provide information on various alternatives for different types of regulation, it is hard to believe that this information was difficult to obtain (EPA 1983). Of course, it is nearly impossible to test whether the EPA did everything it could have done, but we can 
examine whether the agency utilized the available information it developed in its benefit-cost analysis. We examine cases where the RIA presented some measure of the costs or benefits of the regulatory proposal and did not do so for alternatives. In such cases, the absence of key information for an alternative when such information was presented for the proposed method suggests that the information could have been provided, perhaps at some additional cost. Of the sixty RIAs that monetized at least some costs and considered at least one alternative, eleven did not monetize at least some costs of alternatives. Of the thirty-seven RIAs that monetized at least some benefits and considered at least one alternative, thirteen did not monetize at least some benefits of alternatives. Of the forty-four RIAs that calculated net benefits or cost-effectiveness and considered at least one alternative, ten did not calculate net benefits or cost-effectiveness of alternatives. Finally, sixteen of the thirty-nine RIAs that monetized at least some costs and benefits did not calculate net benefits for the proposal.

Consistent with earlier research, we also identified a number of cases in which the agencies quantified but did not monetize benefits. For example, our sample includes two RIAs that quantified lives saved but did not monetize any benefits, even though the Value of Statistical Life has been studied extensively. This suggests that limited knowledge and resource constraints do not offer a complete explanation for why the agency chose not to develop certain benefit estimates, since the additional expenditures for monetizing these benefits are, in these two cases, trivial.

\section{Trends in Quality and Variation in Quality}

Based on the results from our scorecard, we find no clear trend in the quality of benefit-cost analysis across administrations. While these results do not rule out the possibility that RIAs are improving in ways we did not measure, they do show that some basic information is missing from RIAs in all three administrations. What is missing does change over time, but, as indicated in the figures, there is no clear trend. For example, figures 3 and 5 reveal that while there has been some improvement in the calculation of net benefits and cost-effectiveness, there has also been some decline in the consideration of alternatives. We performed a formal statistical analysis of the data, which also indicated that there is no strong statistical evidence of a change in RIA quality across administrations or time. The detailed methodology and results of this analysis are available online as supplementary material linked to the article.

While there does not appear to be a trend in quality, there does appear to be considerable variation both within and across administrations. To examine this issue further, we constructed two indices consisting of selected variables on which RIAs were scored. The index score for each RIA was defined as the percentage of questions on which the RIA received a positive score. The first index consisted of twenty-eight out of the scorecard's seventy-nine questions. The second index was more restrictive, consisting of the six scorecard items that we thought were particularly important for determining the economic efficiency of a regulation. These were whether the RIA provided (1) a point estimate of total monetized costs, (2) a range for total monetized costs, (3) a point estimate of total monetized benefits, (4) a range for total monetized benefits, (5) a point estimate of total net benefits, and (6) a range for total net benefits. The correlation between these two indices is 71 percent, which means that an RIA that scored well on one index was likely to score well on the other. We 
examined how the scores of RIAs varied within administrations by graphing both indices over time. We found the variation to be high both within and across administrations. These results and detailed information on the questions that were included in the two indices are available online as supplementary material linked to the article.

\section{Implications and Policy Recommendations}

Overall, the scorecard method is a useful but imperfect tool for evaluating RIAs. Even if a regulatory agency complies with the executive orders and the OMB guidelines, the deeper issue concerning the assessment of quality remains to be addressed. A high score using our criteria does not necessarily mean that the agency performed a high quality analysis because the agency could have masked analytical flaws. For example, the RIA for the rule reducing lead in gasoline was ranked highly by our scorecard and has been rated a high quality regulation by Morgenstern (1997). The RIA for the National Ambient Air Quality Standards for Ozone also scored very well, but the analysis has been sharply criticized. Although the RIA includes important economic information, some of the RIA's assumptions are faulty. The cost estimates are not substantiated, and the beneficial role of ozone in blocking UV-B radiation was ignored (Lutter and Gruenspecht 2001). Some regulations, such as information disclosure rules, have benefits that are very hard to quantify and are therefore likely to score very low on a scorecard, even if EPA did everything possible to analyze benefits. One example contained in this sample is the addition of industries to the toxic chemical release reporting Community Right-to-Know rule.

Other rules may consider alternatives, but not necessarily alternatives that are most attractive from an economic point of view. The scoring used here only measures whether alternatives were considered, not whether they are reasonable or represent all potential alternatives. In many cases, RIAs do not consider carefully options that would allow for more flexibility to achieve social goals at lower costs. This was the case, for example, with recent rules involving lead and arsenic.

Thus, it is unclear from our analysis how many RIAs are of high quality. A low score on the scorecard is an indicator of a potentially poor quality analysis, particularly if the agency did not assess key economic variables, such as the net benefits of a regulation. Many RIAs are missing fundamental economic information, making it difficult to effectively use the RIAs to make informed policy decisions. If quality is partly measured by the extent to which an RIA can contribute to better decision making, our analysis suggests that many RIAs are of poor quality.

\section{Why Are the Scores So Low?}

A critical question raised by the results of our study is why compliance with benefit-cost requirements appears to have been relatively low and shows no clear sign of improving. We believe that there are several possible explanations. One possible explanation is that the approach of political institutions toward the regulatory policy process has not changed much over the time period examined here. Congress has been willing to support some analysis of regulations to help inform the policy process, but it is not ready to let economic analysis drive the political debate on many issues. The president recognizes the need to introduce greater transparency and accountability into the regulatory process, but regulation is not generally 
an area where he wishes to spend limited political capital. While this explanation is consistent with the data, there are other explanations as well. For example, agency appointees, at the EPA and elsewhere, do not face a strong incentive to do high quality analysis. They are generally rewarded for promulgating and implementing regulations, not studying them.

Moreover, analysis may be viewed only as a necessary evil. Indeed, there appear to be few sanctions for doing poor analysis. In addition, regulatory analyses are expensive to perform, and agencies often do not have the funding to conduct them effectively. Finally, there is limited political support for improving the economic analysis of pending regulations.

An agency's RIA could receive a low score for at least three reasons. First, the agency may face resource constraints. A thorough benefit-cost analysis requires a great deal of scientific and economic information, and the EPA may not have the resources to do the necessary research. Previously, however, we examined evidence that suggested that resource constraints are not a complete explanation for why the agency chose not to develop certain benefit estimates. Nonetheless, it may not always be feasible to quantify some benefits, for example, which can lead to lower scores.

A second reason is that the agency may not want interested parties to know that the benefits of the regulation may not justify the costs. Previous research suggests that a significant number of government rules would not pass a benefit-cost test based on those costs and benefits that had been quantified (Freeman, 2002; Hahn et al., 2000). Specifically, Hahn et al. (2000) looked at several agencies during the Clinton administration and found that of the thirty-one RIAs that provided estimates of costs and benefits that were sufficient to calculate net benefits, only half had benefits and cost savings that exceeded the costs. Three-fourths of RIAs that calculated net benefits passed a benefit-cost test, while only one-third of RIAs that did not calculate net benefits pass a benefit-cost test. Alternatively, the EPA may not compare costs and benefits because the agency does not believe the comparison is instructive. For example, there may be too many benefits or costs that are not quantified for the comparison to be valuable. Even when all information is not available, however, we think it is useful to report a net benefit estimate with caveats than to not present one at all. In addition, the EPA might not want to admit that a decision was the result of a political compromise. Alternatively, the EPA may be reluctant to criticize a decision that was essentially made by Congress or the president.

Third, the agency may simply not take the RIA requirement seriously because it is not enforced. We suspect that lack of political will on the part of the Executive Office of the President is a major factor in the high degree of noncompliance. There is a significant political cost to changing the behavior of a regulatory agency, but the political payoffs of doing so are typically low (Noll 1999).

\section{Recommendations for Reform}

There are many possible paths for reform - too numerous to mention here (Breyer, 1993; Hahn, 2000; Noll, 1999). If the aim is to improve the quality and transparency of analysis, we would recommend two modest changes: the first is more vigilant oversight by the OMB; the second is to use a standardized "Regulatory Impact Summary" that would accompany each regulatory impact statement (Farrow, 2000; Hahn and Sunstein, 2002). 
More vigilant oversight by the OMB would put agencies on notice that the executive order requiring benefit-cost analysis needs to be taken seriously. Such efforts, to be effective, would require high-level White House support either from the vice president or the president. In addition, it would be helpful if Congress lent its support.

The regulatory impact summary requirement could be implemented more easily by the $\mathrm{OMB}$. By requiring agencies to submit such a summary with each proposed regulation, the $\mathrm{OMB}$ would encourage agencies to pay more attention to whether their analyses meet fundamental criteria. For example, if an agency is required to report whether it has quantified and monetized pollution benefits, identified a best estimate for the regulation's expected net benefits, or identified the dollar year in which it has stated its estimates, the agency will be less inclined to submit an analysis that ignores these features.

We do not believe this requirement would impose a significant burden on the agency because it does not require more analysis - only a summary of the analysis the agency has already done. Responding to a standardized set of straightforward questions about that analysis should require a minimal amount of extra time and resources.

The benefits of this exercise, however, could be significant. Such a summary could keep agencies focused on the key requirements of the executive orders. It could help regulators and decision makers determine the strengths and weaknesses of the underlying analysis. It would also facilitate a straightforward assessment of the degree to which regulatory analyses are meeting several important criteria. A standardized summary would also encourage standardized RIAs, which currently, vary widely in format.

The two changes suggested above could help make the regulatory process more transparent. Aside from being desirable for its own sake, this would serve two important purposes. First, it would give interested parties greater access to a key part of the regulatory process used to support a decision. Second, it would increase the probability that scholars would engage in independent regulatory analysis that could lead to improvements in regulation. Thus, greater transparency could both improve the decision-making process and create a better foundation for evaluating the analytical basis for decision making.

\section{Conclusion}

This article has provided a systematic examination of a select sample of benefit-cost analyses that span the Reagan, George H. W. Bush, and Clinton administrations. Our principal finding is that fundamental economic information was not reported in many of the RIAs, including information on relevant policy alternatives and information on net benefits. The EPA's analyses frequently did not provide adequate information about a proposed regulation to justify decisions to proceed with that regulation. The absence of information on net benefits is especially unfortunate because it is so closely linked to the goals of the executive orders. In addition, many RIAs lacked adequate summaries.

Our analysis also suggests that many RIAs are of poor quality. Despite the limitations of the scorecard method, we believe that a low score on the scorecard is likely to be correlated with an analysis that experts would say was done poorly. Future research is needed to explore whether expert judgment about the quality of a regulatory analysis is correlated with the scorecard approach used here. 
We believe that all of the administrations could have done better in complying with the spirit and letter of the relevant executive orders and OMB guidelines. Because our sample covers two Republican presidents and one Democratic president, the lack of compliance cannot be explained simply by the party of the president.

The picture we paint here is not as rosy as we would have hoped. Indeed, some academics have suggested to us that government benefit-cost analysis may be doomed because it is done in an intensely political environment. While it is true that such analyses are done in intensely political environments, this does not imply that they cannot be done better or used more effectively. Academics can be helpful here in two ways: first, by characterizing the impact of benefit-cost analysis in the real world, and second, by defining better ways to apply this tool that are also politically feasible.

We offer one final thought that should give the optimists - those of us who see a constructive role for benefit-cost analysis - some reason for cheer. We are all relatively new at this game, especially in terms of real-world implementation. Knowledge about new processes accrues, and frequently diffuses, slowly. We are guardedly optimistic that benefit-cost analysis will be used more effectively twenty-five years from now than it is used today, precisely because we will have learned more about its strengths and limitations in real-world settings.

\section{Supplementary Data}

Supplementary data for this article are available online at http://www.reep.oxfordjournals. org.

\section{References}

Ackerman, Frank, and Lisa Heinzerling. 2002.

Pricing the priceless: Cost-benefit analysis of environmental protection. University of

Pennsylvania Law Review 150, no. no. 5: 1553-84.

Adler, Matthew D, and Eric A. Posner., eds. 2000.

Cost-benefit analysis: Legal, economic and

philosophical perspectives. Chicago, IL: University of Chicago Press.

Arrow, Kenneth J., Maureen L. Cropper, George C. Eads, Robert W. Hahn, Lester B. Lave, Roger G.

Noll, Paul R. Portney, Milton Russell, Richard

Schmalensee, V. Kerry Smith, and Robert N.

Stavins. 1996. Is there a role for benefit-cost

analysis in environmental, health, and safety

regulation? Science 272: 221-22.

Breyer, Stephen. 1993. Breaking the vicious circle:

Toward effective risk regulation. Cambridge, MA:

Harvard University Press.

Chichilnisky, Graciela. 1997. The costs and benefits of benefit-cost analysis. Environment and

Development Economics 2: 202-6.
Clinton, William J. 1993. Executive Order 12,866: Regulatory planning and review. Public Papers of the Presidents. Washington, DC: General Printing Office. (September).

Crandall, Robert W., Christopher DeMuth, Robert W. Hahn, Robert E. Litan, Pietro S. Nivola, and Paul R. Portney. 1997. An agenda for federal regulatory reform. Washington, DC: American Enterprise Institute and Brookings Institution. Environmental Protection Agency. 1983. Guidelines for performing regulatory impact analysis. Washington, DC.

Farrow, Scott. 2000. Improving regulatory performance: Does executive office oversight matter? Working paper, AEI-Brookings Joint Center for Regulatory Studies.

Freeman, A. Myrick III. 2002. Environmental policy since Earth Day 1: What have we gained? Journal of Economic Perspectives 16,, no. no. 1 Winter: $125-46$. 
General Accounting Office. 1997. Information contained in EPA's regulatory impact analyses can be made clearer. Washington, DC: U.S. Government Printing Office.

-1998. Agencies could improve development, documentation, and clarity of regulatory analyses. Washington, DC: U.S. Government Printing Office.

Hahn, Robert W. 2000. Reviving regulatory reform: A global perspective. Washington, DC:

AEI-Brookings Joint Center for Regulatory Studies.

Hahn, Robert W., Jason K. Burnett, Yee-Ho. I. Chan, Elizabeth A. Mader, and Petrea R. Moyle. 2000. "Assessing regulatory impact analyses: The failure of agencies to comply with executive order 12,866." Harvard Journal of Law and Public Policy 23,, no. no. 3: 859-77. (Summer).

Hahn, Robert W., and Cass R. Sunstein. 2002. A new executive order for improving federal regulation? Deeper and wider cost-benefit analysis. University of Pennsylvania Law Review 150,, no. no. 5: 1489-1552.

Harrington, Winston., Richard Morgenstern, and Peter Nelson. 2000. On the accuracy of regulatory cost estimates. Journal of Policy Analysis and Management 19,, no. no. 2: 297-332.

Kelman, Steven. 1981. Cost-benefit analysis: an ethical critique. Regulation, 33-40.

Lave, Lester B. 1982. The strategy of social regulation: Decision frameworks for policy. Washington, DC: Brookings Institution.

Lutter, Randall, and Howard Gruenspecht. 2001. Assessing benefits of ground-level ozone: What role for science in setting national air quality standards? Regulatory analysis. AEI-Brookings Joint Center for Regulatory Studies.

Morgenstern, Richard D, ed. 1997. Economic analysis at EPA: Assessing regulatory impact. Washington, DC: Resources for the Future.

Morrall, John F. 2003. Saving lives: a review of the record. Journal of Risk and Uncertainty 27,, no. no. 3: 221-37.

Noll, Roger G. 1999. The economics and politics of the slowdown in regulatory reform. Washington, DC: AEI-Brookings Joint Center for Regulatory Studies.

Office of Management and Budget. 1996. Economic analysis of federal regulations under Executive
Order 12,866. Washington, DC: U.S. Government Printing Office, (OMB Guidelines 1996).

2001. Report to congress on the costs and benefits of federal regulations. Washington, DC: U.S. Government Printing Office.

2002. Report to congress on the costs and benefits of federal regulations. Washington, DC: U.S. Government Printing Office.

2004. Report to congress on the costs and benefits of federal regulations. Washington, DC: U.S. Government Printing Office.

2005. Draft report to congress on the costs and benefits of federal regulations. Washington, DC: U.S. Government Printing Office.

Portney, Paul R. 1990. Economics and the clean air act. Journal of Economic Perspectives 4, no. no. 4: 173-81.

Raiffa, Howard. 1970. Decision analysis: Introductory lectures on choices under uncertainty. Reading, MA: Addison-Wesley.

Reagan, Ronald. 1981. Executive order 12,291: Federal regulation. Public Papers of the Presidents. Washington, DC: General Printing Office. (February).

Renda, Andrea. 2006. Impact assessment in the EU: The state of the art and the art of the state. Brussels: Center for European Policy Studies.

Smith, V. Kerry, ed. 1984. Environmental policy under Reagan's executive order: The role of benefit-cost analysis. Chapel Hill: University of North Carolina Press.

Stokey, Edith., and Richard. Zeckhauser. 1978. A primer for policy analysis. New York: W. W. Norton. Sunstein, Cass R. 2002. Risk and reason: Safety, law and the environment. Cambridge: Cambridge University Press.

Viscusi, W. Kip. 1996. Economic foundations of the current regulatory reform efforts. Journal of Economic Perspectives 10,, no. no. 3: 119-34.

Viscusi, W. Kip., and James T. Hamilton. 1999. Are risk regulators rational? The American Economic Review 89: 1010-27.

Weidenbaum, Murray. 1997. Regulatory process reform: From ford to clinton. Regulation 20, no. no. 1: 20-26.

White, Lawrence J. 1981. Reforming regulation: Processes and problems. Englewood Cliffs, NJ: Prentice Hall. 